\title{
HYPOTHESIS
}

\section{The null oncogene hypothesis and protection from cancer}

\author{
M P Davenport, R L Ward, N J Hawkins
}

J Med Genet 2002;39:12-15

Tumour progression involves the inactivation of tumour suppressor genes and the activation of proto-oncogenes. Inactivation of both copies of a tumour suppressor gene is required for carcinogenesis, while germline deletion or inactivation of one copy results in an increase in the risk of cancer and is responsible for many of the known hereditary cancer syndromes. In contrast, activation of only one copy of a proto-oncogene is required for carcinogenesis. Germline deletion or inactivation of one copy of a proto-oncogene halves the risk of activation at this locus. We propose that studies of high risk cancer patients will show such "null oncogene" mutations.
See end of article for authors' affiliations

.......

Correspondence to: Dr M Davenport, Department of Pathology, University of New South Wales, Kensington, NSW 2052, Australia;

m.davenport@unsw.edu.au

Revised version received 10 September 2001 Accepted for publication 1 October 2001
M ost hereditary cancer syndromes, such as familial adenomatous polyposis (FAP) and the Li-Fraumeni syndrome, involve the germline inactivation of "tumour suppressor genes" and are dominantly inherited." Tumour suppressor genes normally function as "stop" signals for cell division, but are inactivated during carcinogenesis, resulting in unregulated cell division. However, the presence of one functional copy is sufficient to maintain function, and thus both copies of the gene need to be inactivated for carcinogenesis (Knudson's "two hit" hypothesis ). ${ }^{2}{ }^{3}$ If the spontaneous mutation rate is $\mathrm{M}$, the probability of one mutation occurring at a given tumour suppressor gene locus is $2 \mathrm{M}$ (that is, two alleles, sum of $M$ for each allele). The probability of the second allele being affected is $M$ (there being only one remaining normal copy). Thus the probability of both copies of a tumour suppressor gene being inactivated independently (in sporadic cancer) is the product of these, $2 \mathrm{M} \times$ $\mathrm{M}=2 \mathrm{M}^{2}$. Since most familial cancers involve the constitutive inactivation of one copy of a tumour suppressor gene, only the second "hit" (with probability $M$ ) is required to inactivate the remaining functional copy (fig 1).

Oncogenes are derived from proto-oncogenes that normally act within the cell to promote cellular replication (a "Go" signal). Carcinogenesis involves alteration of these genes by amplification, translocations, and point mutations, resulting in constitutive activation of the gene products, and a continuous drive for cell replication. The possibility that inactivation of protooncogene alleles may also occur, in either germline or somatic cells, and as a result of genetic or epigenetic change, has received scant consideration in cancer publications. We consider that inactivation of a proto-oncogene, which we have termed a "null oncogene", may have a significant, albeit more subtle impact on neoplastic progression.
Oncogene mediated progression within a cell requires only one "Go" signal, and thus only one copy of the cellular proto-oncogene needs to be activated by mutation. Since the cell normally has two copies of the proto-oncogene, the probability of at least one being mutated is $2 \mathrm{M}$ (that is, the sum of the probability of $M$ for each). However, if one copy of the proto-oncogene is deleted or constitutively inactivated (a "null oncogene"), the probability of a mutation activating the remaining one is only $\mathrm{M}$. That is, the risk of mutational activation of the proto-oncogene, and thus of subsequent neoplastic progression, is halved (fig 1).

The null oncogene hypothesis predicts that the presence of a germline null oncogene will reduce the risk of cancer, and that null oncogenes will be found in human populations at significant risk of cancer development.

\section{TESTING THE HYPOTHESIS}

\section{Null oncogenes and animal models}

Animal models clearly provide an opportunity to explore the role of null oncogenes. Interestingly, some models of this phenomenon may already exist. A murine model has been developed involving a heterozygous "knockout" mouse in which one copy of the Grb2 gene has been inactivated. ${ }^{4}$ Grb2 (growth factor receptor bound protein-2) is an adaptor protein implicated in several human malignancies, including breast carcinoma. ${ }^{56}$ When these heterozygous Grb2 knockout mice were bred with transgenic mice genetically predisposed to the development of mammary tumours, the time taken to develop these tumours almost doubled. ${ }^{4}$ One explanation for this event is that it is the result of a reduced probability of an activating mutation, although the Grb2 gene in the tumour was not sequenced. However, the effects of reduced gene function may also have been of importance, since it was observed that the growth of the normal breast tissue in the heterozygous Grb2 knockout mice was significantly retarded.

This illustrates a potential secondary effect of a null oncogene. If the presence of only one functional copy of a proto-oncogene quantitatively decreases the function of the gene in normal cellular replication (a smaller "Go" signal), this may act independently to reduce the risk of neoplastic progression. For example, a reduction in cell numbers or cell turnover in an organ may reduce the number of cellular "targets" in which mutations can arise. Similarly, decreased cell turnover may reduce the proliferation of cells carrying mutations in other genes, thereby decreasing the possibility of these cells acquiring further mutations. ${ }^{78}$ Reduced basal levels of expression of proto-oncogenes may also 
A Sporadic cancer:

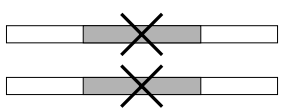

Tumour suppressor gene

$\left(2 M^{2}\right)$

B Familial cancer:

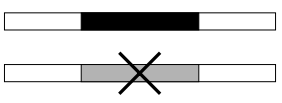

Tumour suppressor gene

(M)

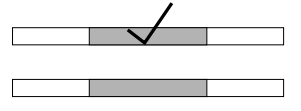

Proto-oncogene

(2M)

Cancer

$=4 \mathrm{M}^{3}$

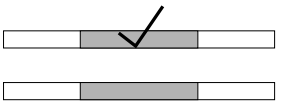

Proto-oncogene

(2M)

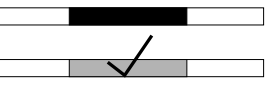

Proto-oncogene

(M)
Cancer

$=2 M^{2}$

Cancer

$=M^{2}$

Figure 1 A simplified model of the development of cancer. Carcinogenesis requires both inactivating mutations $(x)$ in tumour suppressor genes and activating mutations $(\mathrm{V})$ in proto-oncogenes. The probability of a mutation inactivating a tumour suppressor gene or activating a proto-oncogene is $M$. In sporadic cancer, the risk of inactivating both copies of a tumour suppressor gene and activating at least one copy of a proto-oncogene can be calculated as $4 \mathrm{M}^{3}$ (A). Most hereditary cancers involve the constitutive inactivation (black) of a tumour suppressor gene, increasing the risk of cancer to $2 \mathrm{M}^{2}$ (B). By contrast, the constitutive inactivation of a proto-oncogene produces the "null oncogene effect" and reduces the risk of both sporadic and familial cancer by half (C).

inhibit the carcinogenic effects of mutations in other genes. Proto-oncogene protein products are components of complex signalling pathways leading to cell proliferation, and other members of these pathways are reliant on normal levels of expression of the proto-oncogene to transduce their signals. Where a particular proto-oncogene is a rate limiting step in an important signalling pathway, reduced levels of expression owing to the null oncogene effect will act as a "bottle neck" to negate the effects of mutational activation of other genes in the pathway.

The relative importance of the decreased risk of mutational activation and the decreased gene function of a protooncogene may vary depending on the gene and tumour involved. In many cases, gene function may be unimpaired by the presence of only one functional copy of the gene. However, where normal gene function is reduced, this may act synergistically with the reduced probability of mutational activation of the proto-oncogene to reduce the risk of cancer further. Future proto-oncogene "knockout" studies in mice predisposed to cancer should aim to sequence the proto-oncogene within the tumour and to measure the rate of cell proliferation. This will allow a more detailed analysis of the effects of a null oncogene.

\section{Null oncogenes in human populations}

To date, there has been no systematic search for germline null mutations of oncogenes. In fact, since the presence of cancer is the usual criterion for the study of oncogenes, there is an inbuilt bias against the detection of protective mutations. Analysis of the null oncogene effect in human populations will first require the identification of a sufficient number of carriers of the genes.

Both gain of function and loss of function mutations of the RET proto-oncogene have been found. ${ }^{9}{ }^{10}$ Germline loss of function of one copy of the RET proto-oncogene is identifiable because of its association with Hirschsprung disease (congenital megacolon). ${ }^{11-13}$ Germline mutations leading to gain of function of the RET proto-oncogene are associated with multiple endocrine neoplasia syndrome type 2 (MEN 2). ${ }^{14}$ Somatic mutations in the RET proto-oncogene are also frequent in sporadic medullary thyroid carcinomas. ${ }^{9}{ }^{14}$

The null oncogene hypothesis predicts that the germline inactivation of the RET proto-oncogene in Hirschsprung disease patients should lead to lower rates of thyroid and endocrine neoplasms in these patients. Studies of the rates of endocrine neoplasia in Hirschsprung disease patients are complicated by a small subgroup of patients who have point mutations in either codons 609,618 , or 620 , and have both Hirschsprung disease and MEN 2. It seems that these point mutations lead to both decrease in receptor expression (resulting in Hirschsprung disease) and constitutive dimerisation (activation) leading to MEN 2. ${ }^{10}{ }^{16}{ }^{17}$ However, these point mutations represent only a small minority of the mutations found in Hirschsprung disease, many of which include large deletions or frameshifts which result in decreased RET expression without constitutive dimerisation. The hypothesis predicts that patients with a null mutation in the RET protooncogene should have lower rates of sporadic thyroid carcinoma and perhaps other endocrine neoplasms than the general population (fig 2). 
A

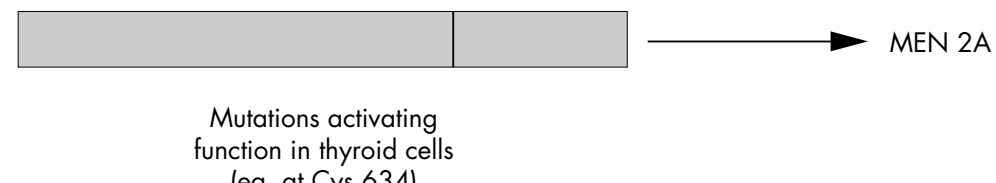

(eg, at Cys 634)

B

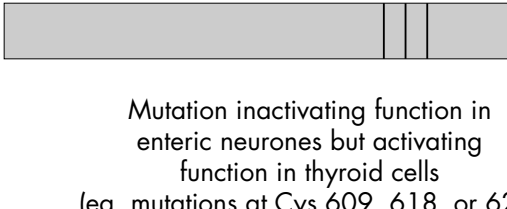

(eg, mutations at Cys 609, 618, or 620)

C

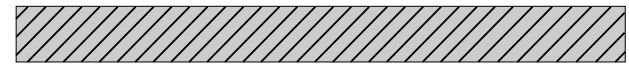

Complete loss of function

(eg, frameshift mutation)
Hirschsprung disease + reduced risk of cancer (null oncogene effect)

Figure 2 Predicting a decreased risk of cancer in patients with Hirschsprung disease. Germline RET mutations that result in a constitutive dimerisation of receptor (gain of function) may lead to MEN 2A (A). Mutations that lead to decreased expression of the receptor but constitutive dimerisation of the remaining receptor result in Hirschsprung disease and MEN 2A (B). However, the null oncogene hypothesis predicts that mutations which result in a complete loss of function of RET should lead to Hirschsprung disease and a reduced rate of thyroid carcinoma (C). ${ }^{1617}$

Null oncogene mutations are unlikely to be very common, both because they have not been observed during studies of oncogenes to date and because homozygosity for null oncogene mutations may be lethal. The search for other null mutations in human proto-oncogenes should focus on long term survivors from populations at high risk of cancer. For example, activating point mutations of the K-RAS protooncogene occur in up to $50 \%$ of colon cancers. ${ }^{18}$ Studies of familial adenomatous polyposis (FAP) patients with late onset disease may show null mutations of this proto-oncogene. Identification of patients carrying null oncogene mutations will enable direct analysis of the effects of these mutations on the risk of cancer in humans.

\section{CONCLUSIONS}

Theoretical predictions of the effects of germline null oncogene mutations suggest that functional haploidy at oncogene loci may result in reduced rates of cancer. This prediction is supported by the results of experiments in transgenic mice. Germline mutations of proto-oncogenes are one obvious cause of oncogene inactivation, and the discovery of null oncogene mutations in Hirschsprung disease suggests the possibility that these mutations may be present in the human population. It is also important to consider that epigenetic modification of genes may lead to inactivation of one copy of an oncogene. This is interesting to consider in the context of genomic imprinting, where monoallelic expression of both tumour suppressor and oncogenes may occur as a result of silencing of the gene derived from one parent. ${ }^{19}{ }^{20}$

Demonstration of the null oncogene effect may well have future therapeutic implications for patients at high risk of cancer. If the effect in FAP patients was of a similar magnitude to that observed in mice, then this may delay the age at which cancer develops from the fourth to the eighth decade. The theoretical analysis and mouse models suggest that inactivation of one allele of a proto-oncogene using somatic gene therapy, for example, may be well tolerated and result in significant reductions in cancer risk.
...................

\section{Authors' affiliations}

M P Davenport, N J Hawkins, Department of Pathology, University of New South Wales, Kensington, NSW 2052, Australia

R L Ward, Department of Medical Oncology, St Vincent's Hospital, Darlinghurst, NSW 2010, Australia

\section{REFERENCES}

1 Fearon ER. Human cancer syndromes: clues to the origin and nature of cancer. Science 1997;278: 1043-50.

2 Knudson A. Mutation and cancer: statistical study of retinoblastoma. Proc Natl Acad Sci USA 1971;68:820-3.

3 Hethcote $\mathbf{H}$, Knudson A. Model for the incidence of embryonal cancers: application to retinoblastoma. Proc Natl Acad Sci USA 1978;75:2453-7.

4 Cheng AM, Saxton TM, Sakai R, Kulkarni S, Mbamalu G, Vogel W, Tortorice CG, Cardiff RD, Cross JC, Muller WJ, Pawson T. Mammalian Grb2 regulates multiple steps in embryonic development and malignant transformation. Cell 1998;95:793-803.

5 Daly RJ, Binder MD, Sutherland RL. Overexpression of the Grb2 gene in human breast cancer cell lines. Oncogene 1994;9:2723-7.

6 Verbeek BS, Adriaansen-Slot SS, Rijksen G, Vroom TM. Grb2 overexpression in nuclei and cytoplasm of human breast cells: a histochemical and biochemical study of normal and neoplastic mammary tissue specimens. J Pathol 1997;183:195-203.

7 Ames BN, Gold LS. Too many rodent carcinogens: mitogenesis increases mutagenesis (published erratum appears in Science 1990;249:1487). Science 1990;249:970-1

8 Cohen SM, Ellwein LB. Cell proliferation in carcinogenesis. Science 1990;249:1007-11

9 Pasini B, Ceccherini I, Romeo G. RET mutations in human disease. Trends Genet 1996;12:138-44.

10 Hansford JR, Mulligan LM. Multiple endocrine neoplasia type 2 and RET: from neoplasia to neurogenesis. J Med Genet 2000;37:817-27.

11 Edery $\mathbf{P}$, Lyonnet $\mathrm{S}$, Mulligan LM, Pelet A, Dow E, Abel L, Holder S, Nihoul-Fekete C, Ponder BA, Munnich A. Mutations of the RET proto-oncogene in Hirschsprung's disease. Nature 1994;367:378-80.

12 Romeo G, Ronchetto P, Luo Y, Barone V, Seri M, Ceccherini I, Pasini B, Bocciardi $R$, Lerone $M$, Kaariainen $H$, Martucciello $G$. Point mutations affecting the tyrosine kinase domain of the RET proto-oncogene in Hirschsprung's disease. Nature 1994;367:377-8.

13 Pasini B, Borrello MG, Greco A, Bongarzone I, Luo Y, Mondellini P, Alberti L, Miranda C, Arighi E, Bocciardi R, Seri M, Barone V, Radice MT, Romeo G, Pierotti MA. Loss of function effect of RET mutations causing Hirschsprung disease. Nat Genet 1995; 10:35-40.

14 Hofstra RM, Landsvater RM, Ceccherini I, Stulp RP, Stelwagen T, Luo Y Pasini B, Hoppener JW, van Amstel HK, Romeo G, Lips CJ, Buys CH. A' 
mutation in the RET proto-oncogene associated with multiple endocrine neoplasia type $2 \mathrm{~B}$ and sporadic medullary thyroid carcinoma. Nature 1994;367:375-6

15 Mulligan LM, Eng C, Attie T, Lyonnet S, Marsh DJ, Hyland VJ, Robinson BG, Frilling A, Verellen-Dumoulin C, Safar A, Venter DJ, Munnich A, Ponder BAJ. Diverse phenotypes associated with exon 10 mutations of the RET proto-oncogene. Hum Mol Genet 1994;3:2163-7.

16 Chappuis-Flament S, Pasini A, De Vita G, Segouffin-Cariou C, Fusco A, Attie T, Lenoir GM, Santoro M, Billaud M. Dual effect on the RET receptor of MEN 2 mutations affecting specific extracytoplasmic cysteines. Oncogene 1998;17:2851-61.
17 Takahashi M, Iwashita T, Santoro M, Lyonnet S, Lenoir GM, Billaud M. Co-segregation of MEN2 and Hirschsprung's disease: the same mutation of RET with both gain and loss-of-function? Hum Mutat 1999:13:331-6.

18 Bos JL. The ras gene family and human carcinogenesis. Mutat Res 1988; 195:255-71.

19 Barlow DP. Gametic imprinting in mammals. Science 1995;270:1610-13

20 Jirtle RL. Genomic imprinting and cancer. Exp Cell Res 1999;248: 18-24.

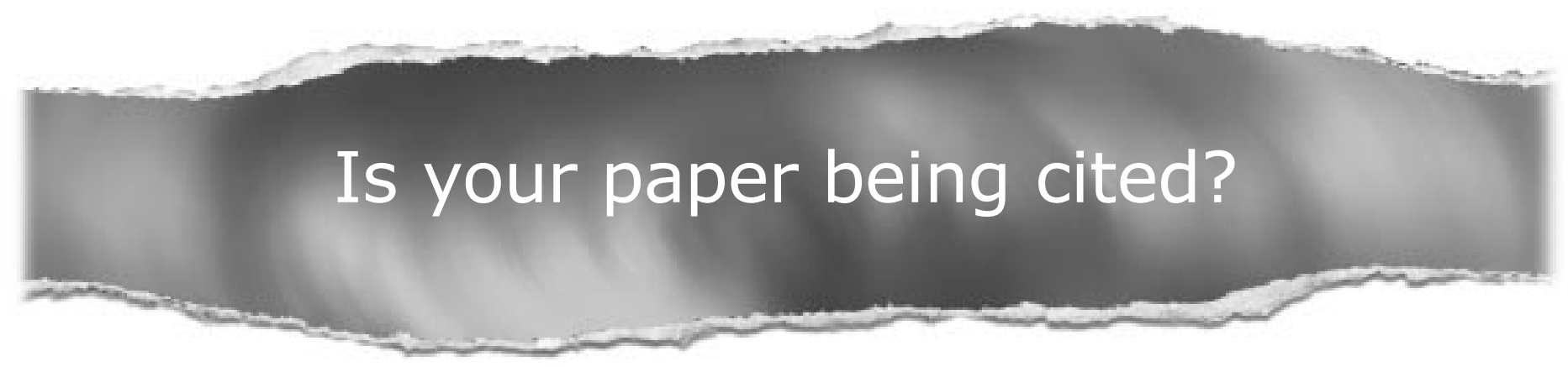

\section{CiteTrack service}

CiteTrack will alert you by email whenever new content in the Journal of Medical Genetics or a participating journal is published that matches criteria you want to track

Topics: Tell CiteTrack which words or subjects to watch for in new content Authors: Be alerted whenever key authors you are following publish a new paper Articles: Know whenever a paper of interest to you is referenced by another paper

www.jmedgenet.com 